\title{
PREPARATION OF ACTIVATED CARBON FROM TEAK LEAVES FOR THE DECOLORIZATION OF PALM OIL
}

\author{
E. I. Ofulue ${ }^{1}$, F. A. Adekola ${ }^{1}$, and V. O Adimula ${ }^{1} *$ \\ ${ }^{1}$ Department of Industrial Chemistry, University of Ilorin, P.M.B. 1515, Ilorin, Nigeria. \\ *Corresponding Authors: faadekola@ yahoo.fr; vincentadimula@gmail.com \\ Received 13 July 2020; accepted 23 July 2020, published online 28 August 2020
}

\begin{abstract}
The bleaching efficiency of activated carbon prepared from teak leaves was investigated for the removal of pigments from palm oil. The adsorbents were activated using $\mathrm{KOH}$ and $\mathrm{FeCl}_{3}$ as activating agents. The effects of adsorbent dosage $(2 \%-6 \%)$, contact time $\left(15 \mathrm{~min} .-90 \mathrm{~min}\right.$.) and temperature $\left(30^{\circ} \mathrm{C}-80\right.$ $\left.{ }^{\circ} \mathrm{C}\right)$ were studied, while the unactivated adsorbent was used as standard. The ash content, moisture content, volatile matter content, and fixed carbon content were determined and the adsorptive bleaching of palm oil investigated using $1.2 \mathrm{~g}$ activated carbon with $20 \mathrm{~g}$ crude palm oil. Bleaching efficiency was observed to be $93.09 \%$ and $96.68 \%$ for the $\mathrm{KOH}$ and $\mathrm{FeCl}_{3}$ activated adsorbent respectively, while the unactivated adsorbent was observed to have a bleaching efficiency of $89.21 \%$. The optimum bleaching efficiency was observed at a temperature of $70^{\circ} \mathrm{C}$, adsorbent dosage of $6 \%$, and contact time of $90 \mathrm{~min}$. Results obtained suggests that teak leaves can be a source of low-cost adsorbent for the removal of pigments from palm oil which is of great relevance in obtaining a clean environment.
\end{abstract}

Keywords: Teak leaves, activated carbon, adsorbents, bleaching efficiency, clean environment

\section{Introduction}

Elaeis guineensis (commonly called oil palm or African oil palm) has been reported as a source of palm oil which is an edible oil obtained from the mesocarp of the oil palm fruit. The use of the palm oil as components of food products has drawn a lot of attention from research owing to contamination concerns which can impact negatively on human health. In its raw form, palm oil contains impurities such as left over particles of oil seed, gums and waxes, organic pigments, phosphates, and trace metals. For palm oil to be edible for consumption and also for its industrial use and application, these impurities which affects its suitability must be eliminated. This makes refining of palm oil through the action of adsorptive bleaching applicable in oil refining industry [1-4]. The processing techniques from the fresh oil palm fruit include traditional methods and small-scale to large scale industrial milling. The bleaching process helps to remove pigments and other impurities that negates the suitability of palm oil for its desired purpose. This is achieved by contacting the oil with a surface-active substance that adsorbs the undesired particles. The decolorization (bleaching) process can be achieved by either chemical treatment, heat treatment or adsorption method which is the most widely and effectively used method. Thus, in this research work, adsorptive bleaching was carried out using activated carbon adsorbent. Adsorptive bleaching usually requires the use of materials which have adsorptive properties that can be exploited to achieve effective removal of the impurities of interest [1, 2, 5]. Activated carbon is usually produced from naturally occurring materials which can be chemically or physical treated using chemical reagents with heat. Researchers have made attempts to develop efficient adsorbents which can be used as readily available substitutes for the imported adsorbents in the refining of palm oil [6-9].

Activated carbon has been accepted by most industries as efficient, cost effective adsorbent due to its advantage of availability, profitability, and efficiency. Producing inexpensive activated carbon is one of the main challenges of commercial manufacturing. To this end, new production techniques and the use of inexpensive raw materials have been researched into including the use of agricultural waste as an inexpensive precursor with high carbon content and low inorganic content. Activated carbon produced from locally sourced materials (corn hub, rice husk, and coconut shells) have been 
reported to be competent in the adsorptive bleaching process for palm oil over the years due to its high adsorptive power [2, 3].

To the best of our knowledge, there is no report of the preparation of activated carbon from teak leaves for the bleaching of palm oil. Thus, we report the optimal bleaching efficiency with respect to adsorbent dosage, contact time, and temperature for the use and relevance of activated carbon produced from teak leaves as an adsorbent in the bleaching of palm oil.

\section{Experimental}

\subsection{Material and Instruments}

The teak leaves were obtained from the teak plantation located in the University of Ilorin, Ilorin, Nigeria. The crude palm oil was obtained locally from a market located at Tanke, Ilorin. Potassium hydroxide $(\mathrm{KOH})$, ferric chloride $\left(\mathrm{FeCl}_{3}\right)$, and $\mathrm{N}$-hexane were obtained from British Drug House, England, and used as obtained. Fourier transform infrared (FTIR) spectroscopy analysis was carried out using a Nicolet iS5 FTIR Instrument using $\mathrm{KBr}$ pellets at the Department of Chemistry, University of Ilorin, Nigeria, while the UV-Vis spectroscopy analysis was carried out using a Beckman UVVis spectrophotometer.

\subsection{Chemical activation}

Samples of dried teak leaves were collected in batches from the teak plantation present in the school environment; thoroughly washed, dried and subsequently stored. The collected teak leaves were further air dried to remove moisture contents and ground to reduce the surface area. The crushed leaves were carbonized with the use of a muffle furnace at $500-600{ }^{\circ} \mathrm{C}$ for about 40 minutes after which it was allowed to cool. The cooled carbon was ground to powder form with the use of a mortar and pestle after which it was sieved to ensure equal fineness of the powder. About $15 \mathrm{~g}$ of carbonized teak leaf was weighed each into two separate glass jars and each was dissolved with different activating agents [10].
The first glass jar containing the weighed carbonized teak leaf was dissolved in $100 \mathrm{ml}$ of $0.5 \mathrm{M} \mathrm{KOH}$ while another $15 \mathrm{~g}$ carbonized teak leaves was weighed into a second jar and dissolved in $100 \mathrm{ml}$ of $5 \% \mathrm{FeCl}_{3}$, for about 24 hours, after which they were both dried in an electric oven at a temperature of $105^{\circ} \mathrm{C}$. The dried activated carbon was filtered and subsequently washed with distilled water and kept in an electric oven at a temperature of $105^{\circ} \mathrm{C}$ for the purpose of drying. The activating agents were added in aliquots with rigorous stirring. The activated carbon prepared were then stored for further characterization $[2,10]$.

\subsection{Evaluation of Bleaching Performance}

To measure the absorbance of the crude palm oil $\left(\mathrm{A}^{\circ}\right), 0.006 \mathrm{~g}$ of the unbleached palm oil was diluted in $5 \mathrm{ml}$ of $\mathrm{N}$-Hexane and its absorbance was determined for wavelengths in the range of $380 \mathrm{~nm}-520 \mathrm{~nm}$. The maximum wavelength was then determined to be $450 \mathrm{~nm}$.

\subsection{Optimization of Adsorption Kinetics}

For the adsorption kinetics experiment, $20 \mathrm{~g}$ of crude palm oil was weighed into six $100 \mathrm{ml}$ beakers and optimized with carbonized teak leaf on a magnetic stirrer for the respective adsorbent dosage, bleaching time and temperature. This was determined by evaluating the bleaching performance after each optimization $[1,11]$. The samples as contained in the six conical flasks were optimized at dosages of $2 \%, 3 \%, 4 \%$, $5 \%, 6 \%$ at respective times of $15 \mathrm{~min} ., 30 \mathrm{~min}$., 45 min., 60 min., 75 min., $90 \mathrm{~min}$. and at temperatures of $30^{\circ} \mathrm{C}, 40^{\circ} \mathrm{C}, 50^{\circ} \mathrm{C}, 60^{\circ} \mathrm{C}, 70^{\circ} \mathrm{C}$, $80{ }^{\circ} \mathrm{C}$.

The bleaching efficiency of the activated carbon sample was then determined by measuring the amount of pigment in the bleached oil using a UV visible spectrophotometer. The samples were diluted in $\mathrm{N}$-Hexane and the absorbance of the samples were determined at a wavelength of $450 \mathrm{~nm}$ using the UV visible spectrophotometer. In this work, the efficiency of the adsorbents used was expressed in terms of absorbance of light passing through the medium (crude and bleached palm oil), which was then converted 
into percentage color reduction of the bleached oil $[2,12]$.

Bleaching Performance $=\frac{100\left(A_{0}-\mathrm{A}\right)}{A_{0}}$

$\mathrm{A}_{0}=$ absorbance of crude palm oil.

$\mathrm{A}=$ Absorbance of bleached palm oil.

\subsection{Adsorptive bleaching}

Adsorptive bleaching was achieved by charging $20 \mathrm{~g}$ per batch of the crude palm oil along with $1.2 \mathrm{~g}$ of activated carbon into a $100 \mathrm{ml}$ beaker. The feed charged was heated and stirred continuously on a magnetic stirrer regulated at a temperature of $70{ }^{\circ} \mathrm{C}$ for 90 minutes. At the completion of the time, the mixture was filtered through a Whatmann No.1 filter paper and the concentration of pigment in the filtrate was determined by a U-VisV spectrophotometer [1].

\section{Results and discussion}

\subsection{Physico-chemical Characterization}

The physico-chemical characterization of the adsorbents produced from teak leaves are presented in the Table 1. Ash is non-carbon or mineral content of a substance. This does not combine chemically with the carbon surface which consists of various undesired mineral substances which become more concentrate on activation and comprises of 1-20\% content primarily depending on the type of raw material. High ash content is undesirable for activated carbon because it reduces the mechanical strength of carbon and affects adsorptive capacity [13-18].
Table 1: Physico-chemical characterization of adsorbents.

\begin{tabular}{|c|c|c|c|}
\hline Parameters & $\begin{array}{l}\text { Unactivate } \\
\text { d Carbon }\end{array}$ & $\begin{array}{l}\text { KOH } \\
\text { A.C }\end{array}$ & $\mathrm{FeCl}_{3}$ A.C \\
\hline $\begin{array}{l}\text { Moisture } \\
\text { content }(\%)\end{array}$ & 3.11 & 5.36 & 7.32 \\
\hline Ash content & 4.00 & 3.70 & 3.30 \\
\hline $\begin{array}{l}\text { Volatile } \\
\text { matter (\%) }\end{array}$ & 27.47 & 36.54 & 9.34 \\
\hline $\begin{array}{l}\text { Fixed carbon } \\
(\%)\end{array}$ & 65.42 & 54.40 & 80.04 \\
\hline $\begin{array}{l}\text { Bulk Density } \\
\left(\mathrm{gcm}^{-3}\right)\end{array}$ & 0.286 & 0.326 & 0.294 \\
\hline $\mathrm{Ph}$ & 8.0 & 9.9 & 3.0 \\
\hline $\begin{array}{l}\text { Conductivity } \\
\left(\mathrm{sm}^{-1}\right)\end{array}$ & 0.7 & 0.6 & 1.0 \\
\hline TDS (ppm) & 1.42 & 4.39 & 7.22 \\
\hline
\end{tabular}

Table 1 above indicates that the moisture content of activated carbon prepared with $\mathrm{FeCl}_{3}$ is higher than the other materials prepared, while the volatile and ash content are lower. Due to its high fixed carbon content it is therefore a preferred adsorbent with respect to the other two.

\subsection{FTIR analysis results}

The FTIR spectra of the adsorbents produced; unactivated carbon, $\mathrm{KOH}$ activated carbon and $\mathrm{FeCl}_{3}$ activated carbon showed major adsorption bands before and after adsorption (fig. 1-3). It can be seen that there is a slight reduction in the stretching vibration adsorption bands which clearly indicates the adsorption of ions on the adsorbent by physical forces. The unactivated carbon produced showed bands at: $3398.43 \mathrm{~cm}^{-1}$ due to the $v(\mathrm{OH})$ stretching vibrations; $2917.15 \mathrm{~cm}^{-1} \& 2860.16 \mathrm{~cm}^{-1}$ due to the $v(\mathrm{C}-\mathrm{H})$ stretching vibrations of alkanes; $1587.34 \mathrm{~cm}^{-1}$ due to the $v(\mathrm{C}=\mathrm{C})$ stretching of cyclic alkenes; $1441.68 \mathrm{~cm}^{-1}, \quad 798.94 \mathrm{~cm}^{-1}, \quad 713.46 \mathrm{~cm}^{-1}$, $665.96 \mathrm{~cm}^{-1}, 646.97 \mathrm{~cm}^{-1}$ due to the $v(\mathrm{C}-\mathrm{H})$ bending vibrations; $1093.40 \mathrm{~cm}^{-1}$ due to the $v(\mathrm{C}$ O) stretching vibrations; and $874.93 \mathrm{~cm}^{-1}$ due to bending of the $v(\mathrm{C}=\mathrm{C})$ bonds before adsorption. 


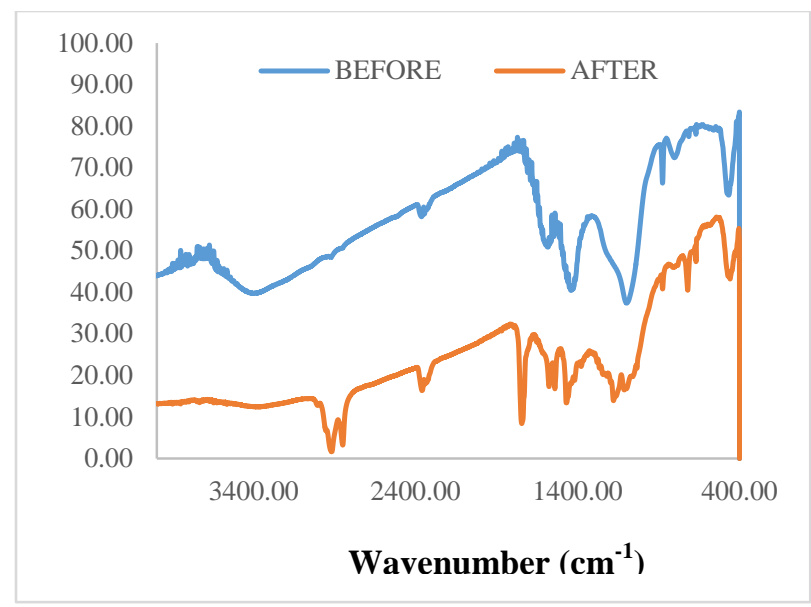

Fig. 1: Adsorption bands of unactivated carbon before and after adsorption.

After the adsorption process, bands characteristic of the $v(\mathrm{OH})$ stretching vibrations were observed to be absent in the unactivated carbon prepared while the band was observed at $1742.48 \mathrm{~cm}^{-1}$ was attributed to the $v(\mathrm{C}=\mathrm{O})$ stretching vibration of esters due to the adsorbed palm oil pigment on the adsorbent.

Before adsorption, the $\mathrm{KOH}$ activated carbon (Fig. 2) showed bands at: $3401.58 \mathrm{~cm}^{-1}$ due to the $v(\mathrm{OH})$ stretching vibrations; $1590.50 \mathrm{~cm}^{-1}$ due to the $v(C=C)$ stretching vibration of cycloalkenes; $1429.02 \mathrm{~cm}^{-1}$ due to the $v(\mathrm{C}-\mathrm{H})$ stretching of alkanes; $1052.24 \mathrm{~cm}^{-1}$ due to the $v(\mathrm{C}-\mathrm{O})$ stretching of primary alcohols; 871.77 $\mathrm{cm}^{-1}, 786.28 \mathrm{~cm}^{-1} \& 719.79 \mathrm{~cm}^{-1}$ due to the $\mathrm{v}(\mathrm{C}=\mathrm{C})$ bending of alkenes, $669.13 \mathrm{~cm}^{-1}$ due to the bending of the $v(C=C)$ of alkenes.

After adsorption however the spectra showed no bands due to the stretching of the $v(\mathrm{OH})$ group but rather showed bands at: $1745.65 \mathrm{~cm}^{-1}$ due to the $v(C=O)$ stretching of esters; $3012.14 \mathrm{~cm}^{-1}$, $2917.15 \mathrm{~cm}^{-1} \& 2850.66 \mathrm{~cm}^{-1}$ due to the $v(\mathrm{C}-\mathrm{H})$ stretching vibrations of alkenes and alkanes. Figure 3 above shows the spectra of the $\mathrm{FeCl}_{3}$ activated carbon with bands observed at: $3385.75 \mathrm{~cm}^{-1}$ due to the stretching vibration of the $v(\mathrm{OH}) ; 1603.17 \mathrm{~cm}^{-1}$ due to the $v(\mathrm{C}=\mathrm{C})$ stretching vibration of conjugated alkenes; $1093.40 \mathrm{~cm}^{-1}$ due to the $\mathrm{v}(\mathrm{C}-\mathrm{O})$ stretching vibrations; $805.28 \mathrm{~cm}^{-1}$ due the $\mathrm{v}(\mathrm{C}=\mathrm{C})$ bending of alkenes before adsorption.

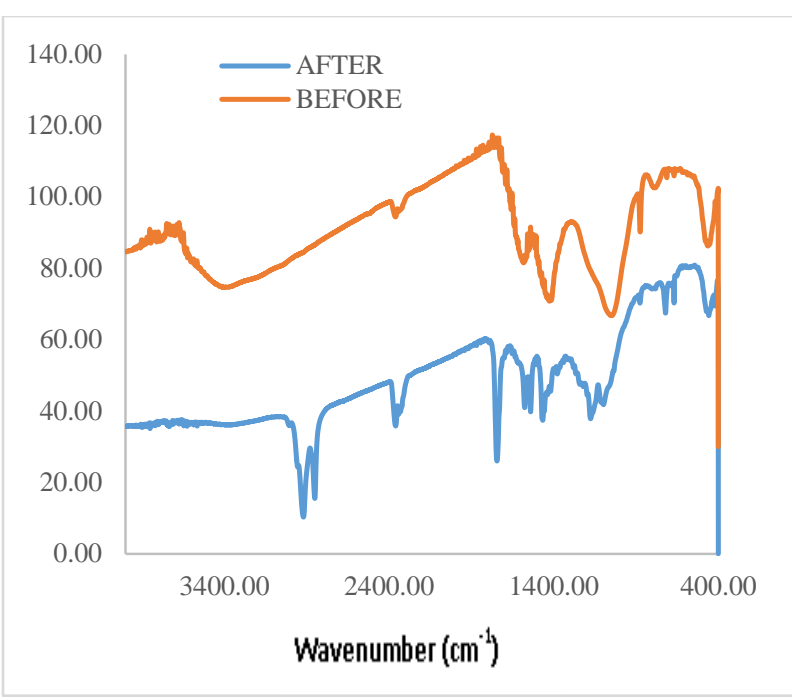

Fig. 2: Adsorption bands of $\mathrm{KOH}$ activated carbon before and after adsorption.

FTIR spectra of the $\mathrm{FeCl}_{3}$ activated carbon is presented in Figure 3. The spectra shows bands observed at: $3385.75 \mathrm{~cm}^{-1}$ due to the stretching vibration of the $v(\mathrm{OH}) ; 1603.17 \mathrm{~cm}^{-1}$ due to the $\mathrm{v}(\mathrm{C}=\mathrm{C})$ stretching vibration of conjugated alkenes; $1093.40 \mathrm{~cm}^{-1}$ due to the $v(\mathrm{C}-\mathrm{O})$ stretching vibrations; $805.28 \mathrm{~cm}^{-1}$ due the $\mathrm{v}(\mathrm{C}=\mathrm{C})$ bending of alkenes before adsorption. The $v(\mathrm{OH})$ band was observed to be shifted to $3363.59 \mathrm{~cm}^{-1}$ after the adsorption process, while bands observed at $2920.32 \mathrm{~cm}^{-1} \& 2844.33 \mathrm{~cm}^{-1}$ are attributed to the $v(\mathrm{C}-\mathrm{H})$ stretching of alkanes.

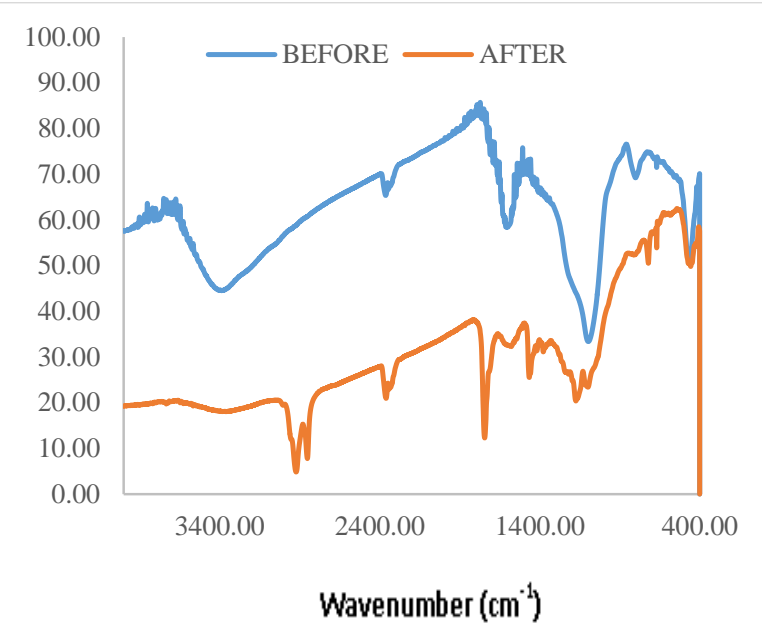

Fig. 3: Adsorption bands of $\mathrm{FeCl}_{3}$ A.C before and after adsorption. 


\subsection{Adsorption kinetics}

Adsorption kinetics experiment was carried out using $20 \mathrm{~g}$ of crude palm oil and optimized with carbonized teak leaf, and the effects of adsorbent dosage, bleaching time and temperature on the adsorptive bleaching process was determined [1, 2, 19-24]. The wavelength of maximum adsorption $\left(\lambda_{\max }\right)$ determined with the use of a UV-Vis spectrophotometer was obtained in the wavelength range of $380-520 \mathrm{~nm}$ and presented in Figure 4. To determine the wavelength of maximum absorbance $\left(\lambda_{\max }\right), 0.006 \mathrm{~g}$ of the unbleached palm oil was diluted in $5 \mathrm{ml} \mathrm{N}$ Hexane and its absorbance was determined in the wavelength range of $380-520 \mathrm{~nm}$. A plot of wavelength against absorbance gave a value of $450 \mathrm{~nm}$ for the $\lambda_{\max }$. The absorbance of the crude palm oil was observed to decrease rapidly beyond $450 \mathrm{~nm}$. Thus, The $\lambda_{\max }$ value was taken to be $450 \mathrm{~nm}$.

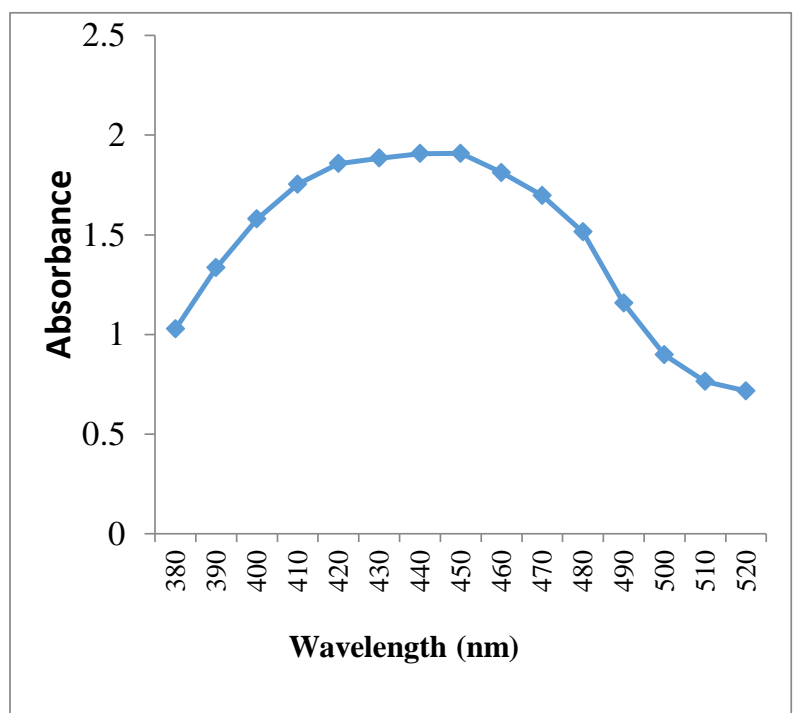

Fig. 4: Plot of wavelength against absorbance to determine the $\lambda_{\max }$

\subsubsection{Effect of contact time}

The effect of contact time on the adsorption process was studied by varying the contact time between 15-90 min. Figure 6 shows a plot of bleaching efficiency against the time for the adsorption process. Bleaching efficiency was observed to decrease with increase in contact time from 15-75 min., after which a sharp

\subsubsection{Effect of adsorbent dosage}

Figure 5 present a plot of the bleaching efficiency of the adsorbents against adsorbent dosage. The dosage was varied from an initial adsorbent dose of $2 \mathrm{~g}$ to $6 \mathrm{~g}$ and it was observed that the bleaching efficiency increased with an increase in adsorbent dose. The bleaching efficiency was observed to increase up to a maximum value of $73.02 \%$ with an adsorbent dose of $6 \mathrm{~g}$.

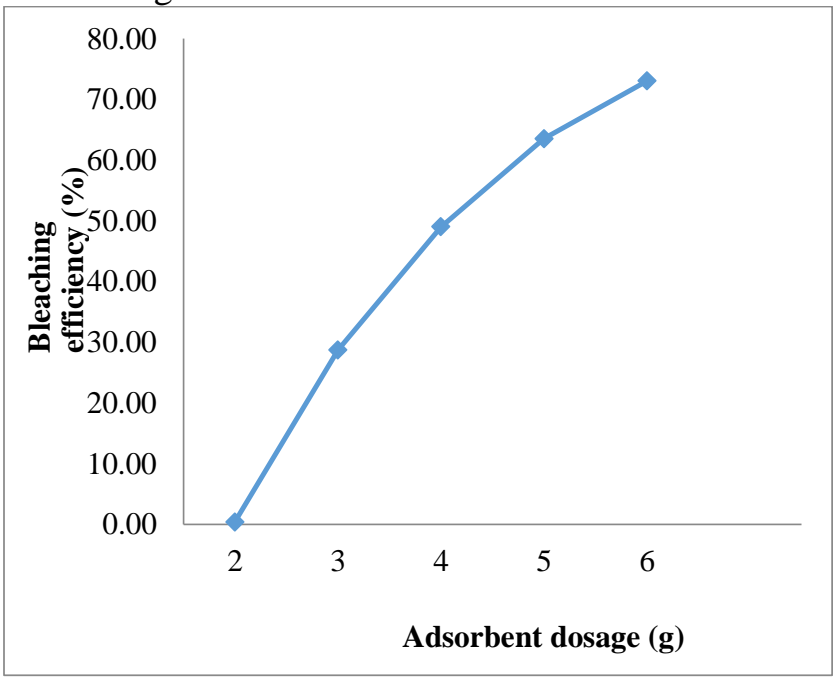

Fig. 5: Plot of bleaching efficiency against adsorbent dosage.

increase in the bleaching efficiency was observed up to a time of $90 \mathrm{~min}$. with $83.60 \%$ bleaching efficiency. 


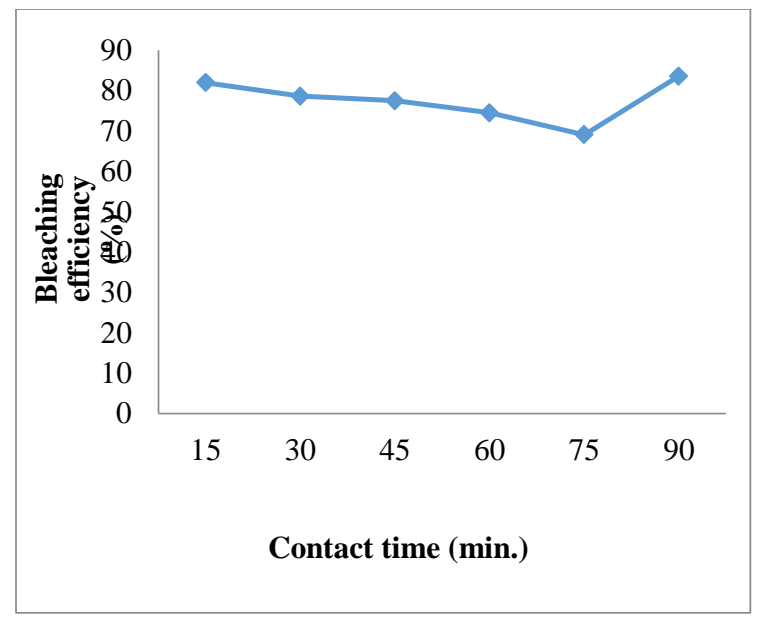

Fig. 6: Plot of bleaching efficiency against contact time.

\subsubsection{Effect of temperature}

A plot of variation of temperature with bleaching efficiency is presented in Figure 7. By varying the temperature of the process from 30 ${ }^{\circ} \mathrm{C}$ to $80^{\circ} \mathrm{C}$, it was observed that an increase in temperature up to about $50{ }^{\circ} \mathrm{C}$ initially caused a decrease in the rate of adsorption thereby resulting in a decrease in the bleaching efficiency. Further increase in temperature from $50{ }^{\circ} \mathrm{C}$ resulted in an increase in the bleaching efficiency up to a temperature of $70{ }^{\circ} \mathrm{C}$, thereafter, bleaching efficiency declined. This is attributed to the saturation of the adsorption sites at $70{ }^{\circ} \mathrm{C}$. This indicates that the bleaching efficiency was most effective at a temperature of $70{ }^{\circ} \mathrm{C}$ with a bleaching efficiency value of $88.32 \%$.

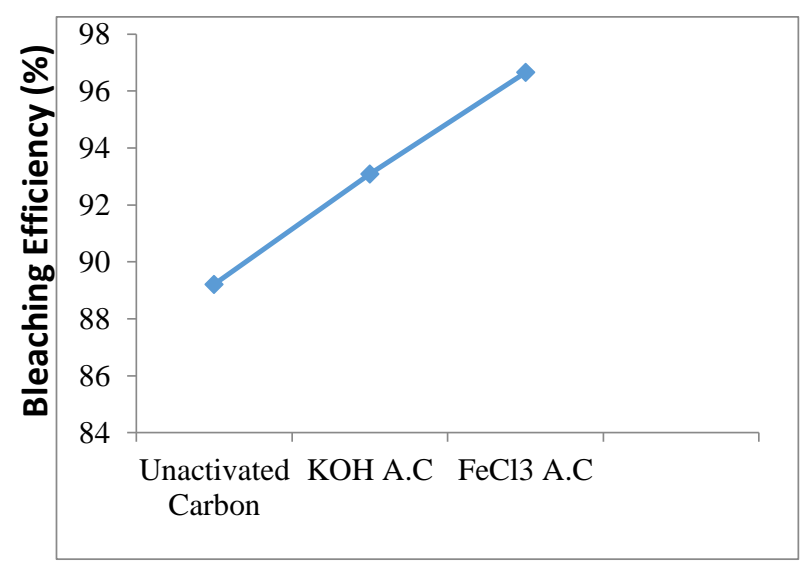

Adsorbents

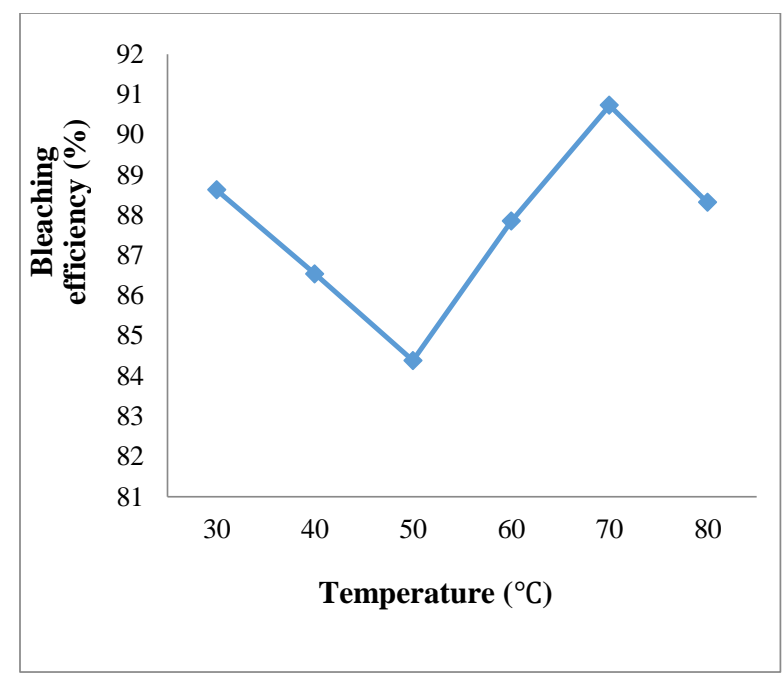

Fig. 7: Plot of bleaching efficiency against Temperature.

3.4. Adsorption data for the bleaching process

From the data obtained as a result of the adsorption kinetics carried out, the bleaching efficiency was maximum at an adsorbent dosage of $6 \mathrm{~g}$, time of 90 minutes, and at a temperature of $70{ }^{\circ} \mathrm{C}$. The bleaching process of crude palm oil sample was then carried out for each adsorbent with the above data obtained.

Table 2: Variation of bleaching efficiency of adsorbents

\begin{tabular}{lll}
\hline Adsorbents & Absorbance & Bleaching Efficiency (\%) \\
\hline $\begin{array}{l}\text { Unactivated } \\
\text { Carbon }\end{array}$ & 0.206 & 89.21 \\
KOH A.C & 0.132 & 93.09 \\
$\mathrm{FeCl}_{3}$ A.C & 0.064 & 96.68 \\
\hline
\end{tabular}

Fig. 8: Variation of bleaching efficiency of adsorbents 
Table 3: Physical and chemical characteristics of bleached palm oil.

\begin{tabular}{|c|c|c|c|}
\hline Characteristics & $\begin{array}{l}\text { Bleached Palm oil } \\
\text { by Unactivated } \\
\text { Carbon }\end{array}$ & $\begin{array}{l}\text { Bleached palm } \\
\text { oil by KOH A.C }\end{array}$ & $\begin{array}{l}\text { Bleached palm oil by } \\
\mathrm{FeCl}_{3} \text { A.C }\end{array}$ \\
\hline Color reduction (\%) & 89.21 & 93.09 & 96.65 \\
\hline Moisture Content (\%) & 1.90 & 3.20 & 4.20 \\
\hline $\begin{array}{l}\text { Yield after adsorption } \\
(\%)\end{array}$ & 88.00 & 83.00 & 86.00 \\
\hline Specific gravity & 0.97 & 0.88 & 0.98 \\
\hline Acid Value & 17.95 & 13.46 & 18.51 \\
\hline Iodine Value & 14.73 & 2.54 & 5.59 \\
\hline Saponification value & 61.71 & 154.27 & 159.89 \\
\hline
\end{tabular}

Data obtained for the optimized adsorptive bleaching of palm oil using the prepared adsorbents and presented in Table 2 and Figure 8 shows that the bleaching efficiency was highest for the $\mathrm{FeCl}_{3}$ activated adsorbent.

\section{Conclusion}

The adsorptive bleaching of palm oil using unactivated carbon, $\mathrm{KOH}$ and $\mathrm{FeCl}_{3}$ activated carbon produced from teak leaves has been successfully investigated. The optimum bleaching condition was equivalent to a bleaching efficiency of $89.21 \%, 93.09 \%$ and $96.68 \%$ for the unactivated carbon, $\mathrm{KOH}$ activated carbon and $\mathrm{FeCl}_{3}$ activated carbon prepared using teak leaf. The highest bleaching efficiency was attained by $\mathrm{FeCl}_{3}$ activated carbon which is due to its high percentage of fixed carbon content, low percentage of ash and volatile matter content. It can be inferred that teak leaves can be converted into potential adsorbents for the bleaching of palm oil which can represent an added value in its utilization and to Nigeria's economy

\section{References}

[1] A. A. Inyinbor, F. A. Adekola, and G. A. Olatunji (2016), Kinetics, isotherms and thermodynamic modeling of liquid phase adsorption of Rhodamine B dye onto Raphia hookerie fruit epicarp, Water Resources and Industry, 15, 14-27.

[2] A. A. Inyinbor, F. A. Adekola, and G. A. Olatunji (2015), Adsorption of rhodamine B dye from aqueous solution on Irvingia gabonensis biomass: kinetics and thermodynamics studies, South African Journal of Chemistry, 68, 115-125

[3] M. A. Usman, O. Oribayo, and A. A. Adebayo (2013), Bleaching of Palm Oil by Activated Local Bentonite and Kaolin Clay from Afashio, Edo-Nigeria, Chemical and Process Engineering Research, 10, 1 - 12.

[4] H. A. Abdul, K. Anuar, Z. Zulkarnain, Z. H. Mohd, K. Dzulkefly, A. Faujan, and O. S. Wooi (2001), Preparation and characterization of activated carbon from gelam wood bark, Department of Chemistry, 7(1), 65-68.

[5] Y. Basiron and C. K. Weng (2004), The oil palm and its sustainability, Journal of Oil Palm Research, 10(1), 1-10.

[6] B. Sivakumar, C. Kannan, and S. Karthikeyan (2012), Preparation and characterization of 
activated carbon prepared from balsamodendron caudatum wood waste through various activation processes, Rasayan Journal of Chemistry, 5(3), 321327.

[7] D. Adinata, W. M. Daud, and M. K. Aroua (2007), Preparation and characterization of activated carbon from palm shell by chemical activation with $\mathrm{K}_{2} \mathrm{CO}_{3}$, Bioresource Technology, 98(1), 145-149.

[8] R. O. Ajemba, P. K. Igbokwe, and O. D. Onukwuli (2012), Optimization of color pigments removal from palm oil by activated Ukpor clay using response surface methodology, Research Journal of Applied Sciences, Engineering and Technology, 6(3), 423-432.

[9] J. Guo and A. Lua (1999), Textural and chemical characterizations of activated carbon prepared from oil palm stone with $\mathrm{H}_{2} \mathrm{SO}_{4}$ and $\mathrm{KOH}$ impregnation, Microporous and Mesoporous Materials, 32(1-2), 111-117

[10] P. O. Agbaire (2012), Quality assessment of palm oil sold in some major markets in Delta State, southern Nigeria. African Journal of Food Science and Technology, 3(9), 223-226.

[11] P. Hariprasad, R. Sivaraj, C. U. Aniz (2016), Preparation and characterization of activated carbon from rice husk, International Research Journal of Engineering and Technology (IRJET), 3(4), 551-558.

[12] M.J. Holden (1982), Manufacture and Uses of Activated Carbon, Effluents and Water Treatment. J., 22(1), 27-46.

[13] M. Ahmednaa, W. E. Marshallb, and R. M. Raoa (2000), Production of granular activated carbons from select agricultural byproducts and evaluation of their physical, chemical and adsorption properties, Bioresource Technology, 71(2), 113-123.

[14] C. I. O. Kamalu, E. C. Osoka, and M. S. Nwakaudu (2012), Bleaching of crude palm kernel oil using activated snail shell, Research Journal in Engineering and Applied Sciences, 1(5) 323-326.

[15] O. M. Lai, C. P. Tan, and C. C. Akoh (2012), Palm oil: Production, processing, characterization and uses, AOCS Press, Beijing, pp 1-10.
[16] J. Laine, A. Calafat, and M. Labady (1989), Preparation and characterization of activated carbons from coconut shell impregnated with phosphoric acid, Carbon, 27(2), 191195.

[17] E. P. Leimkuehler (2010), Production, characterization and applications of activated carbon, M.Sc Thesis. University of Missouri, Columbia. 1-56.

[18] J. E. G. Mdoe and L. L. Mkayula (2002), Preparation and characterization of activated carbons from rice husks and shells of palm fruits, Tanzania Journal of Science, 28(2), 131-142.

[19] S. I. Mustapha A. A. Mohammed, A. Y. Zakari, and H. A. Mohammed (2013), Performance evaluation of local clays from northern Nigeria for the refining of palm oil, Journal of Chemical Engineering and Material Science, 4(5), 58-66. DOI: 10.5897/ JCEMS2013.0152.

[20] A.J. Otaru, C.U. Ameh, A.S. Abdulkareem, J.O. Odigure, and J.O. Okafor (2013), Development and characterization of adsorbent from rice husk ash to bleach vegetable oils, Journal of applied chemistry, 4(2), 42-49.

[21] F. Rodriguez-Reinoso (1989), An Overview of Methods for the Characterization of Activated Carbons, Pure and Appl. Chemistry, 61(11), 1859-1866.

[22] D. Smrutirekha (2014), Characterization of activated carbon of coconut shell, rice husk and karanja oil cake, B.Sc. Thesis, National institute of technology, Rourkela, pp 1-32.

[23] P. Subhashree (2011), Production and characterization of activated carbon produced from a suitable industrial sludge, B.Sc. Thesis, National institute of technology, Rourkela, pp 1-60.

[24] B. Sivakumar, C. Kannan, and S. Karthikeyan (2012), Preparation and characterization of activated carbon prepared from balsamodendron caudatum wood waste through various activation processes, Rasayan Journal of Chemistry, 5(3), 321327. 